\title{
DO SECOND LANGUAGE TEACHERS NEED TO KNOW ABOUT PARAMETERS?
}

\author{
Cecile le Roux \\ Department of General Linguistics \\ University of Stellenbosch
}

\section{Introduction*}

In this paper I shall examine the relationship between linguistics and second language (=L2) teaching with the aim of dispelling the common misconception that linguistics has little of interest to say to L2 teachers.

I shall build my argument on a linguistic claim, viz. the claim that acquiring a language entails the triggering of appropriate values for the parameters associated with universal linguistic principles.

\section{Linguistic background}

The claim that the acquisition of a language entails the triggering of parameters forms part of Chomsky's theory of how children acquire their first language (= L1). On this theory, the child is innately equipped with knowledge of the essential structural properties of human language. This initial knowledge, known as Universal Grammar (UG), takes the form of a number of universal principles of linguistic structure, some of which are associated with one or more open parameters. To give a simple example: it is a universal principle of linguistic structure that a phrase, be it a noun phrase, a verb phrase, an adjectival phrase or a prepositional phrase, consists minimally of a lexical item, its head, which determines the category to which the phrase belongs. In addition to a head, a phrase can, optionally, include constituents known as specifiers and complements. This basic cross-categorial symmetry in the make-up of phrases is illustrated by means of examples from English in (1).

a. Noun phrase (NP)

the enemy's

Specifier destruction

Head $(=N)$ of the city

Complement 
b. Verb phrase (VP)

$\begin{array}{lll}\text { the enemy } & \text { destroyed } & \text { the city } \\ \text { Specifier } & \text { Head }(=\mathrm{V}) & \text { Complement }\end{array}$

c. Adjectival phrase (AP)

$\begin{array}{llll}\text { very } & \text { proud } & \text { of } & \text { the destruction } \\ \text { Specifier } & \text { Head (=A) } & \text { Complement }\end{array}$

d. Prepositional phrase (PP)

$\begin{array}{lll}\text { right } & \text { through } & \text { the destruction } \\ \text { Specifier } & \text { Head (=P) } & \text { Complement }\end{array}$

Now, the principle of UG which expresses the claim that all phrases in human language consist of an obligatory head and an optional specifier and/or complement has associated with it two parameters, each with two possible values or settings, viz. the head direction parameter (2) and the specifier parameter (3): 1

(2) The head direction parameter

(a) Heads precede their complements.

(b) Complements precede their heads.

(3) The specifier parameter

(a) Specifiers are phrase-initial.

(b) Specifiers are phrase-final.

So, although all languages manifest the same general principle, viz. that phrases have obligatory heads and optional specifiers and complements, they differ with regard to the values they assign to the two parameters associated with this principle. This explains the word order variation found across languages, such as that evidenced by the difference between English and Japanese illustrated in (4):

(4) a. English

gave a book to John

Head (V) Complement 
b. Japanese

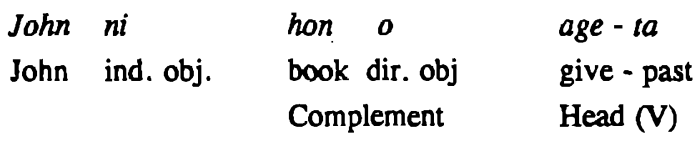

The child acquiring a language already knows the general principle: it is part of her UG, or innate linguistic knowledge. She needs only to determine what value to assign to each of the parameters associated with the principle. In order to do this, the child needs to be exposed to naturally occurring samples of the language. These samples will contain the evidence required to trigger the correct parameter settings. Once the values of all parameters have been fixed, the child is said to have acquired the grammar of that language: the child's knowledge of language has attained its mature, or steady, state. ${ }^{2}$ This view of L1 acquisition is schematically represented in the diagram (5)

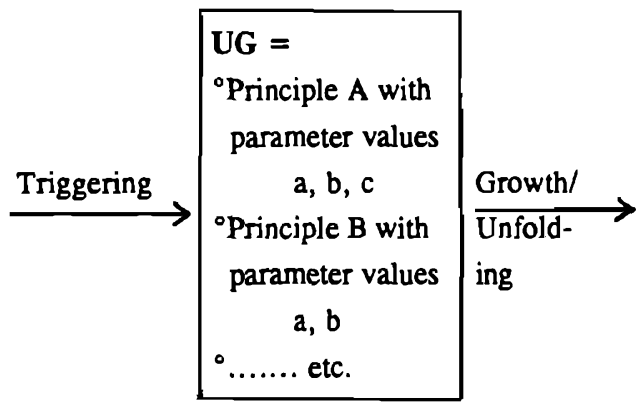

Grammar of $\mathbf{L 1}=$ ${ }^{\circ}$ Language-specific instantiation of A with parameter setting $c$ ${ }^{\circ}$ Language-specific instantiation of B with parameter setting a -....... etc.

Two further points need to be made in connection with Chomsky's views on the nature and acquisition of knowledge of a language. The first concerns the mechanism responsible for acquisition, i.e. the triggering mechanism. The triggering of appropriate values, or settings, for pre-existing parameters takes place unconsciously and automatically. ${ }^{3}$ That is, language acquisition can be likened to the acquisition of vision: given the right kind of external stimuli in the form of light rays, etc., human vision develops, or is triggered, automatically. Chomsky himself uses terms such as "growth" and "unfolding" to describe the development of language from its initial to its mature state. ${ }^{4}$ These metaphors express very strongly the sense of inevitability and automaticity that the term " triggering" is intended to convey.

This brings us to the second aspect of Chomsky's view of language acquisition that needs to be emphasized: the nature of the evidence or input that is required to trigger the appropriate 
parameter settings. Once again, just as the development of typical human vision can take place only if the organism is exposed to a certain type of stimulus or experience, so knowledge of language can develop from its initial to its mature state only if the child receives suitable input. All that is required, according to Chomsky, is that the child be exposed to naturally occurring, suitably contextualised utterances in the language, termed "primary linguistic data" or "evidence". Without such exposure, acquisition will not take place.

But, not only is exposure to primary linguistic data (i.e. naturally occurring utterances) necessary to trigger the appropriate parameter settings, it is also the only type of linguistic input required. This follows from a certain view of the human mind to which Chomsky subscribes: the so-called modular view of mind. We shall return to this point later.

Not all aspects of the $\mathrm{Ll}$ are acquired in the way described above, of course: only the core syntactic features that represent language-specific instantiations of universal properties of language. Specifically, the lexical items (or the words) of the language have to be learnt along with their meanings and quite detailed information concerning the kinds of sentence structures they will fit into. Idioms, along with other less usual constructions and, of course, all the social and cultural conventions relating to the use of the language have to be learnt.

\section{Parameter-triggering and $\mathrm{L} 2$ learning}

As a theoretical linguist, Chomsky is interested first and foremost in answering the question 'What is language?' He is interested in language acquisition only insofar as it sheds light on the nature of language. He asks questions such as 'What properties must a system have in order to be acquirable in principle, given the conditions under which it is acquired?' He is therefore concerned with the logical problem of language acquisition, the question of how it is at all possible, rather than with the actual course of the development of language in real children. Also, for Chomsky, language acquisition equals the acquisition of a first languiage by young children. He has never made any claims about second language acquisition.

At a first glance, therefore, it may seem as though the belief that linguistics, specifically Chomsky's linguistics, has little of interest to say to L2 teachers is well-founded. This conclusion would be premature, however. While it may be true that Chomsky's principles-andparameters theory is not directly relevant to $\mathrm{L} 2$ teaching, I want to claim that it certainly has indirect relevance to the concerns of L2 teachers. To substantiate this claim, I shall briefly sketch the results of research which was stimulated by the desire to explore the consequences of the parameter-triggering view of language acquisition for L2 acquisition. The question that the 
research aims to address is 'What kind of input or evidence do $\mathrm{L} 2$ leamers need in order to acquire knowledge of the grammar of the L2?'

L2 theorists working within a principles-and-parameters framework proceed from the assumption that $\mathrm{L} 2$ knowledge too can be described in terms of principles and parameters, i.e. that L2 grammars, like L1 grammars, are constrained by the set of universal principles and parameters. ${ }^{5}$ L2 acquisition, on this view, proceeds in the same way as L1 acquisition: L2 leamers, on the basis of their exposure to utterances in the $\mathbf{L} 2$, have to set the $\mathrm{L} 2$ values for the parameters associated with the principles of UG in the same way that L1 learners do. ${ }^{6} \mathrm{~L} 2$ leamers differ from L1 leamers in one crucial way only: in the case of L2 learners, the parameters associated with the principles of UG have already had values - the LI values assigned to them. For example, the head direction parameter will already have been set to either the value head-complement, or the value complement-head for the L1. L2 acquisition, therefore, involves the changing of existing parameter settings from the $\mathrm{Ll}$ values to the appropriate $L 2$ values. On this view, $L 2$ acquisition can be schematically represented as follows:

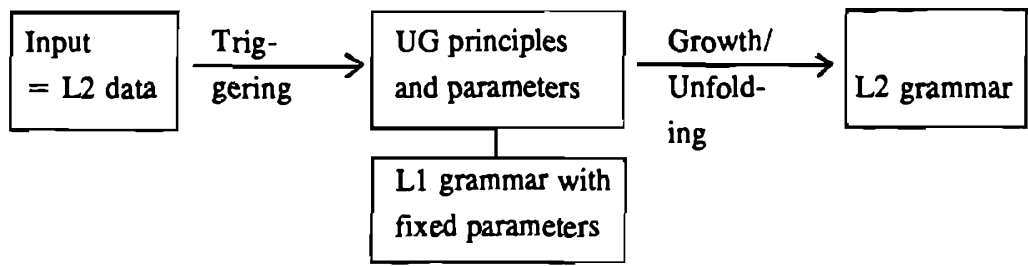

What claims does this view of $\mathrm{L} 2$ acquisition make about the kind of input that L2 leamers need? Let us assume that L2 learners start out by simply transferring the L1 parameter settings to the L2, which is the claim made by Lydia White and her co-researchers to whose work I shall be referring. ${ }^{7}$ Then $\mathrm{L} 2$ leamers clearly need evidence on the basis of which parameter values can be changed. The problem, however, is that the necessary evidence is not always available in naturally occurring samples of the $\mathrm{L} 2$ encountered by the leamer.

White (1987:100-107) describes two kinds of circumstances in which naturalistic L2 input will not provide the evidence necessary to trigger the resetting of a parameter. The first is the situation where the bulk of the input received by the leamer consists in utterances produced by other L2 learners. White (1987:101) cites the example of native speakers of Spanish leaming English. Spanish is a so-called pro-drop language, that is, a language in which subject pronouns can be omitted. So, for instance, He speaks in English can be translated as Parla in Spanish, and It's raining as Piove. Native speakers of Spanish leaming English are known to 
omit subject pronouns in English as well. This means, of course, that much of the input received by someone learning English with them, although it will no doubt be comprehensible, will lack precisely the evidence necessary to cause a change in the value of the pro-drop parameter from the L1 (Spanish) setting to the L2 (English) setting. 8

The second type of situation in which naturalistic L2 input will be inadequate, according to White (1987:103), is one in which even native speaker utterances cannot provide the evidence necessary to cause a change in the value of an Ll parameter. This is typically the case when the leamer needs negative evidence, i.e. evidence that something is not possible, in order to arrive at the correct parameter setting for the language being learnt. Consider the case of a native speaker of French leaming English. In French, adverbs may appear between a verb and its direct object, as in (7a), whereas in English they may not, as shown in (7b):

(7) Jean a bu LENTEMENT son café.
Jean has drunk slowly his coffee.
(b) *John drank SLOWLY his coffee.

A native speaker of English learning French needs only to hear sentences such as (7a), i.e. needs positive evidence in the form of occurring sentences, to realize that French differs from English in allowing adverbs between the verb and the direct object. A native speaker of French leaming English, by contrast, needs nonoccurring sentences such as ( $7 \mathrm{~b})$, or negative evidence, to tell him or her that it is not possible in English to place adverbs between a verb and its direct object. And, of course, nonoccurring sentences such as (7b), by their very nature, will always be absent from the primary linguistic data, or naturally occurring input, which the learner receives. The input that the leamer receives may contain sentences such as those in (8):
(a) John drank his coffee SLOWLY.
(b) John SLOWLY drank his coffee.
(c) SLOWLY, John drank his coffee.
(d) John is SLOWLY drinking his coffee.

From the occurrence of such sentences in the input the learner can justifiably conclude that adverb placement is relatively free in English. Sentences such as (7b) could be absent from the input for purely accidental reasons. The leamer has no way of knowing that the gap is systematic rather than accidental. Moreover, leamers do not look out for nonoccurring forms, or gaps, in the input in the first place. 
The important point is that, given a clearly articulated linguistic theory of the nature of (i) the learner's prior linguistic knowledge (UG), (ii) the leamer's acquired (L1) knowledge, and (iii) the way in which input interacts with these two kinds of knowledge, an important difference between $\mathrm{L} 1$ acquisition and $\mathrm{L} 2$ acquisition emerges: unlike $\mathrm{L} 1$ acquisition, L2 acquisition is not guaranteed, given only sufficient exposure to positive evidence in the form of naturalistic input, or primary linguistic data. In addition to positive evidence, the L2 leamer also needs negative evidence. That is, the $\mathrm{L} 2$ learner needs evidence about certain differences between the $\mathrm{L} 1$ and the L2 which, in the normal course of events, would not be manifest in naturally occurring samples of the L2. ${ }^{9}$

This finding, of course, has important implications for L2 teaching. Following the influential work of another L2 theorist, Stephen Krashen, in the late seventies and early eighties, the received wisdom in L2 teaching has been that there is no difference in essence between L1 acquisition and L2 acquisition. It has been assumed that L2 leamers, like L1 leamers, need only sufficient exposure to contextualised utterances in the L2 (Krashen's "comprehensible input") to acquire the language. It is this assumption that underpins, for example, the approach to $\mathrm{L} 2$ teaching known as the Natural Approach, as well as all other approaches which assume that grammar need not be taught but develops automatically if learners are given the opportunity to engage in meaningful communication in the L2.10

\section{Form-focused instruction and modular minds}

The claim that L2 learners may, in certain circumstances, require negative evidence to reset parameters to their $\mathrm{L} 2$ values implies that there is a place, and indeed a need, for a measure of explicit focus on form and error correction (grammar teaching in conventional terminology) in L2 teaching. From the late eighties through the early nineties a number of empirical studies have been undertaken to investigate this claim. ${ }^{11}$ In these studies the aspect of language which is chosen for form-focused instruction is typically one which causes a potential leamability problem. That is, a property of the $\mathrm{L} 2$ is chosen which is related to a parametrical difference between the $\mathrm{L} 1$ and the $\mathrm{L} 2$, such as the restriction on adverb placement in English for which French-speaking leamers of English need negative evidence. In all cases, the form-focused instruction was carried out in the context of communicative teaching programmes. That is, the instruction was basically communicative in nature, but the materials were specially prepared so as to be conducive to the use of the target feature, and negative evidence in the form of error correction was allowed. 
Results of these studies have been mixed. In tests conducted immediately after the period of instruction, all the studies have noted a marked difference in performance between the experimental groups, i.e. the groups that received negative evidence, and the comparison groups which received no special form-focused instruction. The experimental groups always outperform the comparison groups. Results from follow-up tests conducted after intervals of up to one year have not been so uniformly positive, however. In some cases the effects of the instruction appear not to have been maintained, whereas in other cases the effects appear to have been more lasting.

The question of interest to the L2 researcher, of course, is why form-focused instruction appears to have lasting effects in some cases, but not in others. I shall mention a few of the possible answers that have been suggested and which, in tum, have stimulated further research. Some researchers look for answers in the classroom. They suggest potential explanations such as

i. that the teachers in question may have used different error correction strategies, some of which may be more effective than others; or

ii. that there may be differences in the amount of support that the target feature received in classroom activities and discourse subsequent to the period of formfocused instruction. 12

Others look for answers in the minds of the leamers. They try to explain the varied results of form-focused instruction with reference to a distinction first made by Krashen, viz. the distinction between leamt knowledge and acquired knowledge. Acquired knowledge, according to Krashen, is knowledge that comes about when the properties of naturally occurring comprehended utterances in the target language are unconsciously registered by what he calls "the language acquisition device" in the mind. Leamt knowledge, by contrast, is gained through conscious leaming that takes place when the learner is focusing on the form rather than the meaning of utterances in the target language. Learnt knowledge is not so much knowledge of language, as knowledge about language. Acquired knowledge is knowledge of language: it is what constitutes the speaker's internalized grammar of the L2 and what underlies the production and comprehension of sentences in spontaneous, unreflective language use. Learnt knowledge comes into play only as a conscious monitor, or check, on the way in which acquired knowledge is implemented in careful, or reflective, language use. Leamt knowledge, moreover, cannot become acquired knowledge, according to Krashen. 
Krashen's claim that consciously learnt knowledge about language is distinct from unconsciously acquired knowledge of language is consonant with a certain view of the human mind known as "the modular view of mind" and, more particularly, with the view that knowledge of language constitutes one of the modules of such a mind. ${ }^{13}$ On a modular view, the mind consists of a number of independent and autonomous modules, each dedicated to the processing and interpretation of information of a specific type. The results of the highly specific kind of processing done in the different modules forms the input to the so-called central processor, where the input is integrated with input from a number of non-task-specific central systems. The result is a complex cognitive representation such as that underlying, for instance, the interpretation of an utterance in context. The diagram (9) is a highly simplified graphic representation of the way a modular mind works.
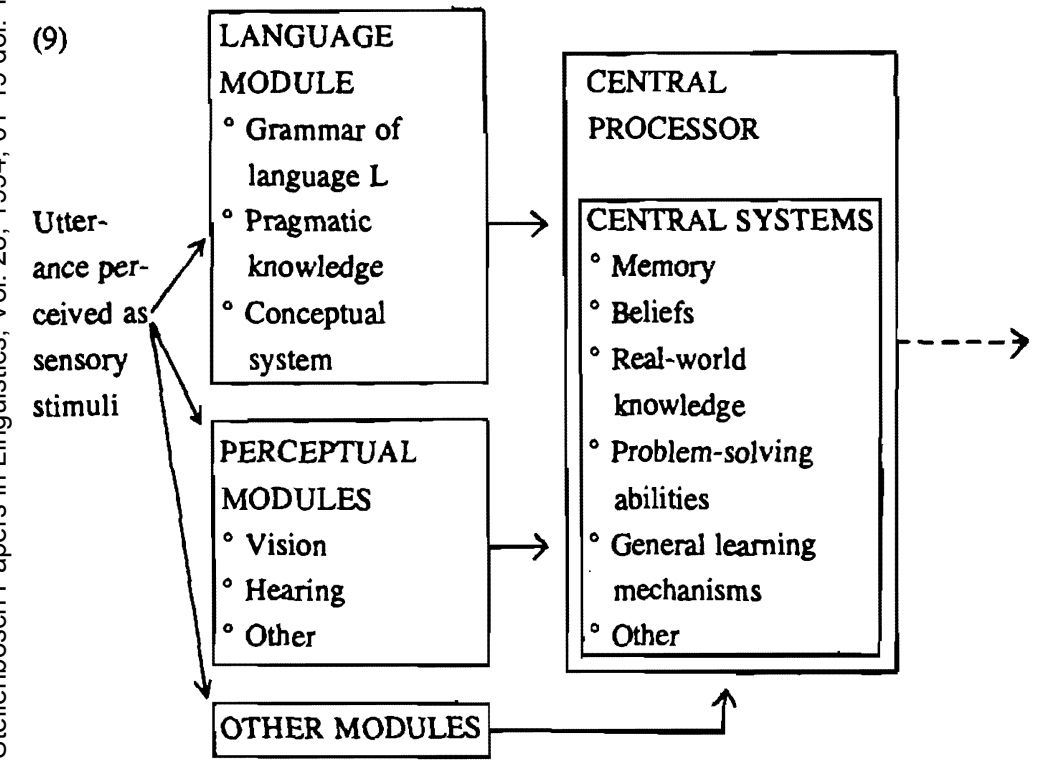

Interpretation assigned to perceived utterance/Utterance assembled for production

Adapted from (White 1989:178) and (Schwartz 1993:157)

Krashen's distinction between acquired and learnt knowledge relates to the modular view of mind in the following way: acquired knowledge, or knowledge of grammar, is part of the language module. Learnt knowledge, or knowledge about language, like other factual knowledge, is situated in the central systems. As the central systems have access to information produced by cognitive modules such as the language module and the vision module, but not the 
other way round, leamt knowledge is not available as input to the language module. Learnt knowledge cannot become acquired knowledge.

But how does a modular view of the human mind explain the different outcomes of formfocused instruction? If the language module is a distinct cognitive module, it follows that, like the other modules, it cannot make use of information that it is not designed to process. Specifically, the mechanism responsible for the acquisition of language neither depends on nor can make use of explicit positive or negative evidence. Explicitly telling a child that $\mathbf{X}$ is possible or that $\mathrm{Y}$ is not possible in the language - that is, giving the child explicit positive or negative evidence - will not lead to a change in the current state of the child's knowledge of language.

Suppose that the language module registers a stimulus representing an utterance of the sentence English is a head-initial language. All the language module can do is to assign the incoming signal a phonological, syntactic and semantic representation. It then sends the result of its operations on to the more global central processor, where information from all the various modules is integrated. The proposition conveyed by the sentence, viz. that English is a headinitial language, is analyzed and stored in the central systems. As there is no feedback from the central systems to the input modules, the knowledge that English is a head-initial language remains just that: knowledge of a fact which happens to be about English. It is no different in essence from, say, the knowledge that the earth rotates around its own axis. It does not affect the leamer's knowledge of English by, for example, triggering the appropriate value of the head-direction parameter. Parameter settings are triggered if the structural properties of sentences and the very fact of their occurrence are registered by the language module. They are not triggered by propositional information about the language which such sentences may happen to convey. 14

It follows, then, that the kind of input provided in form-focused instruction; viz. explicit positive evidence and negative evidence, being propositional or metalinguistic in nature, cannot be processed by the language module and, therefore, cannot result in acquired knowledge. Acquisition requires exposure to primary linguistic data (i.e. naturally occurring utterances), which is the only kind of input the language module can process. Explicit positive evidence and negative evidence can, at best, be processed by the central processor and stored in memory as learnt knowledge, or knowledge about the language. As such, it can affect the leamer's performance on tests conducted shortly after the period of instruction, but whether or not it is retained for a longer period depends on the amount of reinforcement this particular piece of 
knowledge receives. 15 Hence, it is to be expected that the results of post-tests conducted a year after the instruction occurred will be mixed.

Although a modular view of the mind, and the distinction between acquired and learnt knowledge, would appear to account for the varied results of the studies conducted to determine the effects of form-focused instruction, such an account gives rise to another intriguing question. Recall White's claim about the necessity of negative evidence in $\mathbf{L} 2$ acquisition. Certain properties of $\mathrm{L} 2$ grammars, she claims, cannot be deduced on the basis of naturally occurring samples of the L2, such as the utterances in (8) above. Particularly, leamers will, in certain circumstances, not be able to reset parameters associated with linguistic principles to their correct $\mathrm{L} 2$ values without the benefit of negative evidence (i.e. information about the nonoccurrence of certain forms in the L2). The problem, however, is that parameter values are part of knowledge of language, i.e. of the language module. And the language module, we have seen, cannot access information or feedback from other cognitive systems. The knowledge gained on the basis of negative evidence is learnt knowledge, or knowledge about language. As such, it is computed and stored in the central processing systems and cannot bring about a change in parameter settings; it cannot become acquired knowledge. 16

Are we forced, then, to conclude that some aspects of the L2 are simply unacquirable? The mere possibility that this may be the case - and there are other indications, apart from the negative evidence problem, that support this conclusion - raises a host of new and interesting questions about the nature of L2 knowledge and the relationship between (different types of knowledge) and $\mathrm{L} 2$ performance. ${ }^{17}$ To explore these questions lies beyond the scope of this paper, however.

\section{Conclusion}

I want to conclude by returning to the question in the title of my paper: Do second language teachers need to know about parameters? What I hope to have shown is that given a linguistic theory such as the principles-and-parameters theory, which makes precise claims about the nature of linguistic knowledge, the way in which it is acquired and the kind of input necessary for its acquisition, it becomes possible to ask interesting questions about the nature of and the limitations on $\mathrm{L} 2$ acquisition, and about the kind of input required by $\mathrm{L} 2$ leamers. It is of course the task of L2 theorists, not of L2 teachers, to raise these questions and to explore possible answers to them. The answers that these theorists come up with, however, will of necessity have pedagogical implications. They must eventually inform $\mathbf{L} 2$ teaching, as Krashen's answers to these questions informed $\mathrm{L} 2$ teaching by giving rise to the Natural 
Approach. I would argue that an L2 teacher who understands the theoretical basis of a given instructional method is much better equipped to assess it and to apply it with discrimination. For that reason, then, I would say, "Yes, L2 teachers can certainly benefit from knowing about the parameter-triggering view of $\mathrm{L} 2$ acquisition."

It is important to note, in conclusion, that the relationship between linguistics, L2 acquisition theory and L2 teaching is by no means a unidirectional one, with the L2 teacher always on the receiving end. Rather, it is an interactional relationship, as shown in the diagram (10).

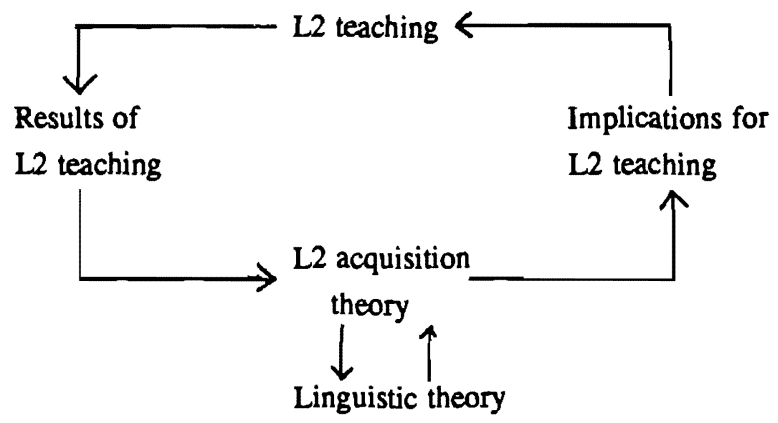

L2 teachers have an important role to play in the testing of L2 theorists' hypotheses, as was shown above in relation to the classroom studies undertaken to determine the role of negative evidence in L2 acquisition. The results achieved in L2 classrooms may cause L2 theorists to revise their initial hypotheses and to raise entirely new questions. The answers to these questions, ultimately, may be used as external evidence for or against linguistic hypotheses about the nature and acquisition of $\mathrm{Ll}$ knowledge. For instance, an answer to the question of whether or not parameters can be reset in the course of L2 acquisition may cast light on the nature of the so-called "steady state" of UG, i.e. the Ll grammar. It may also lead to insight into parameter-triggering as an acquisitional mechanism. ${ }^{18}$

L2 teachers who are theoretically well-informed clearly have a large contribution to make. It should always be borne in mind that, as Schachter (1993:185) puts it,

It is not an obvious or simple step from a theoretical insight to a practical application, nor from a hypothesis to a classroom experiment... .

However, this should not deter L2 teachers from engaging with theories of language and of language acquisition in the interests both of theory and of language teaching practice. 
Notes

* This is a revised version of the text of a paper read at the Fourteenth Annual Conference of the South African Applied Linguistics Association held in Bloemfontein in June 1994.

1. For this particular formulation of the parameters responsible for word order variation across languages, see Atkinson 1992 : 91-92.

2. For some discussion of this view of L1 acquisition, see e.g. Atkinson $1992: 100-104$, Botha 1989 : ch. 2 and White 1989 : ch. 1.

3. The triggering of parameter settings is normally claimed to differ from general leaming processes such as hypothesis formation and testing. But see Atkinson 1992: ch. 8 for an argument to the effect that there is in fact no qualitative difference between parameter-setting and hypothesis formation.

4. See e.g. Chomsky $1980: 134-135$.

5. See Cook 1993 : 205 ff for discussion of the evidence for this assumption.

6.. Of course not all $\mathrm{L} 2$ theorists working within a principles-and-parameters framework accept that UG is still available after puberty. However, a discussion of the potential role of age in L2 acquisition falls outside the scope of this paper. The interested reader can consult (Cook $1993: 204 \mathrm{ff}$ ) for an overview of the various positions on this issue.

7. Note that this is not an uncontroversial assumption. Some researchers have claimed that parameters have default values and that both $\mathrm{L} 1$ learners and $\mathrm{L} 2$ learners start out by assuming the default values until they are forced by the evidence to abandon the assumption. Cf. e.g. Cook $1993: 207$ and White $1989: 50$ for some discussion of this point.

8. Precisely this situation arises in immersion classrooms, it is claimed, with exactly the results described here. Cf. e.g. Hammerly 1987.

9. See e.g. Carroll and Swain 1993, Rutherford and Sharwood Smith 1985 and Schachter 1991 for a discussion of the different forms that negative evidence can take. 
10. See Krashen 1985 for a firsthand account of his views, or Ellis 1985, McLaughlin 1987 or Cook 1993 for an interpretation and critical assessment.

11. See, e.g., White 1991, White et al. 1991, Trahey and White 1993 and Spada and Lightbown 1993, as well as other studies undertaken by Lydia White and the members of the L2 research group at McGill and Concordia Universities. See also the contributions in Eubank (ed.) 1991 and the references in Cook 1993 : chapters 8 and 9.

12. See Spada and Lightbown $1993: 218-219$.

13. See Newmeyer $1983: 2-3$ and par. 1.4, and Botha $1989:$ par. 2.7.3-2.7.4 for discussion of the view that language is a cognitive module. See also Fromkin 1993 for an overview of evidence (from studies of aphasics, brain-damaged children and socalled "idiots savants") for the cognitive autonomy of language. The claim that knowledge of language constitutes a cognitive module is a highly restrictive claim, as a system which is considered to be a cognitive module has certain clearly defined properties which sets it apart from cognitive systems that are taken to belong to the set of general cognitive systems (or central systems). Chomsky first explicitly referred to knowledge of language as "a module" in 1980.

14. See Schwartz and Gubala-Ryzak 1992 and Schwartz 1993 for this argument.

15. This raises the question of what implications, if any, the distinction between acquired and learnt knowledge has for the learner's L2 behaviour. Schwartz (1993: 160) speculates that the distinction will show up in on-line oral production in the L2. Because of the heavy processing load during on-line production, access to items stored in longterm memory (i.e. learnt knowledge) may be inhibited.

16. For a rebuttal of the claim that form-focused instruction (including the provision of negative evidence) cannot bring about developmental changes in the L2, see Lightbown and Pienemann 1993. See also Towell and Hawkins $1994: \mathrm{ch} .11$ for a review of the evidence for and against the claim that "native-like competence" (i.e. acquired knowledge) can result from explicit instruction in the L2. Ellis (1993) and Swain (1993) suggest a potential role for the learner's own learning-based output as a basis for acquisition. Also to be noted in this regard are attempts to provide for some kind of mechanism that can mediate between learnt (i.e. conscious) knowledge and acquired 
(i.e. unconscious) knowledge. One such proposed mechanism is the mechanism of "noticing". With "noticing" is meant that the leamer, on the basis of specially constructed input, is sensitized to (i.e. made conscious of) some feature of the L2. Once the leamer is sensitive to a particular feature of the $\mathrm{L} 2$, this feature becomes "noticeable" (in some sense yet to be made precise) to the language module. That is, whenever the feature occurs in subsequent examples of the language that the learner encounters, it can be processed by the language module so as to become acquired knowledge. See Fotos 1993 and Sharwood Smith 1993 for a detailed account of the role of noticing. See also Van Patten and Cadierno 1993 for what they call "processing instruction", i.e. explicit efforts to help learners notice some targeted feature of the input.

17. Among these are the following:

i. An overview of the studies conducted to determine the role of form-focused instruction in L2 acquisition reveals that in studies which show a sustained positive effect for instruction, the target structure relates to a non-parameterized difference between the $\mathrm{L} 1$ and the L2 (e.g. presentational there is/are in English for L1 speakers of French in (Lightbown 1991)). Studies in which the target structure does relate to a parameterized difference between the $\mathrm{L} 1$ and the $\mathrm{L} 2$, by contrast, do not show a long-term positive effect for form-focused instruction (e.g. adverb position in English for L1 speakers of French in (White 1991) and (Trahey and White 1993)).

ii. Some of the responses produced by the subjects in Trahey and White's (1993) study, as analyzed in (Schwartz and Gubala-Ryzak 1992), indicate that the subjects had simply learned the *S V Adv $O$ pattern that they had been taught, rather than reset the parameter. Evidence for this is the fact that the pattern is wrongly extended to consistently rule out S V Adv PP as well, although forms such as John drives carefully through the park

* are acceptable in English and

* have an analysis (in some cases at least) that does not depend on $\mathrm{V}$ movement, hence on the parameter in question.

Similarly, Hawkins, Towell and Bazergui (1993) found that their subjects behaved in a non-native-like way on constructions other than those that were the focus of instruction. They hypothesize that, although it is compatible with the L2 data, the $\mathrm{L} 2$ grammar differs from that of L1 speakers. Learners, according to them, construct an L2 grammar guided only by the principles of UG and by the parameter settings of the $\mathrm{Ll}$. The fact that the grammar constitutes a 
misanalysis shows up in other constructions than those on the basis of which it was constructed.

iii. It has been hypothesised in recent research that parameters must involve only functional categories (such as Tense and $\mathrm{Agr}$ ). Now, it is remarkable that the most noticeable and consistent problems experienced by L2 learners almost universally are problems with verb morphology, i.e. problems that have to do with tense and agreement. See, e.g., the L2 problems of Christopher, a socalled polyglot savant, whose language learning abilities are described in (Smith, Tsimpli and Ouhalla 1993).

iv. If the "organic growth" metaphor of $\mathrm{L} 1$ acquisition is accurate, then it follows that once all the parameters have been set for the L1, they cannot be reset. The organ will have changed fundamentally. (The fact that bilingualism is possible still has to be accounted for, of course. If parameter settings cannot be changed in L2 acquisition, it would have to be assumed that bilingual individuals entertain two or more parameter settings simultaneously, both those of the L1 and those of the L2, as Cook (1993 : 242-245) has suggested.)

18. See Schachter 1993 : 174-179 for an interesting discussion of some possible contributions of $\mathrm{L} 2$ research to linguistic theory. 


\section{Bibliography}

Atkinson, M. 1992. Children's syntax. An introduction to principles and parameters theory. Oxford: Blackwell.

Botha, R.P. 1989. Challenging Chomsky. The Generarive Garden Game. Oxford: Basil Blackwell.

Carroll, Suzanne and Merrill Swain. 1993. Explicit and implicit negative feedback. An empirical study of the leaming of linguistic generalizations. Studies in Second Language Acquisition 15(3):357-386.

Chomsky, N. 1980. Rules and representations. New York: Columbia University Press.

Cook, V. 1993. Linguistics and second language acquisition. Houndmills and London: Macmillan.

Ellis, R. 1985. Understanding second language acquisition. Oxford: Oxford University Press.

Ellis, R. 1993. The structural syllabus and second language acquisition. TESOL Quarterly 27(1):91-113.

Eubank, L. (ed.) 1991. Point counterpoint. Universal Grammar in the second language. Amsterdam/Philadelphia: John Benjamins Publishing Company.

Fotos, Sandra S. 1993. Consciousness raising and noticing through focus on form: grammar task performance versus formal instruction. Applied Linguistics 14(4):385-407.

Fromkin, Victoria A. 1993. What studies of the brain can tell us about language (if anything) and vice versa. Prodeedings of the nineteenth annual meeting of the Berkeley Linguistics Society: 143-158.

Hammerly, H. 1987. The immersion approach: litmus test of second language acquisition through classroom communication. Modern Language Joumal 71:395-401. 
Hawkins, R., R. Towell and N. Bazergui. 1993. Universal Grammar and the acquisition of French verb movement by native speakers of English. Second Language Research 9(3):189-233.

Hyams, N. 1986. Language acquisition and the theory of parameters. Dordrecht: Reidel.

Krashen, S. 1985. The input hypothesis: issues and implications. London: Longman.

Lightbown, N. 1991. What have we here? Some observations on the influence of instruction on L2 leaming. In Phillipson, R., E. Kellerman, L. Selinker, M. Sharwood Smith and M. Swain (eds.) Foreign/Second language pedagogy research. Clevedon/Philadelphia: Multilingual Matters Ltd., 197-212.

Lightbown, Patsy M. and Manfred Pienemann. 1993. Comments on Stephen D. Krashen's "Teaching issues: formal grammar instruction". TESOL Quarterly 27(4):717-722.

McLaughlin, B. 1987. Theories of second-language learning. London: Edward Ainold.

Newmeyer, F.J. 1983. Grammatical theory. Its limits and its possibilities. Chicago and London: The University of Chicago Press.

Rutherford, W. and M. Sharwood Smith. 1985. Consciousness raising and universal grammar. Applied Linguistics 6:274-282.

Schachter, J. 1991. Corrective feedback in historical perspective. Second Language Research $7(2): 89-102$.

Schachter, J. 1993. Second language acquisition: perceptions and possibilities. Second Lnaguage Research 9(2):173-187.

Schwartz, B.D. 1993. On explicit negative data effecting and affecting competence and linguistic behaviour. Studies in Second Language Acquisition 15:147-163.

Schwartz, B.D. and M. Gubala-Ryzak. 1992. Learnability and grammar reorganization in L2A: against negative evidence causing the unlearning of verb movement. Second Language Research 8(1):1-38. 
Sharwood Smith, M. 1993. Input enhancement in instructed SLA. Theoretical bases. Studies in Second Language Acquisition 15:165-179.

Smith, N.V., I-M. Tsimpli and J. Ouhalla. 1993. Learning the impossible: the acquisition of possible and impossible languages by a polyglot savant. Lingua 91:279347.

Spada, N. and P.M. Lightbown. 1993. Instruction and the development of questions in L2 classrooms. Studies in Second Language Acquisition 15:205-224.

Swain, M. 1993. The Output Hypothesis: just speaking and writing aren't enough. The Canadian Modern Language Review 50(1): 158-164.

Towell, R. and R. Hawkins. 1994. Approaches to second language acquisition. Clevedon, etc.: Multilingual Matters Ltd.

Trahey, M. and L. White. 1993. Positive evidence and preemption in the second language classroom. Studies in Second Language Acquisition 15:181-204.

VanPatten, Bill and Teresa Cadierno. 1993. Explicit instruction and input processing. Studies in Second Language Acquisition 15:225-243.

White, L. 1987. Against comprehensible input: the Input Hypothesis and the development of second-language competence. Applied Linguistics 8:95-110.

White, L. 1989. Universal Grammar and second language acquisition. Amsterdam/Philadelphia: John Benjamins Publishing Company.

White, L. 1991. Adverb placement in second language acquisition: some effects of positive and negative evidence in the classroom. Second Language Research 7(2):133-161.

White, L., N. Spada, P.M. Lightbown and L. Ranta. 1991. Input enhancement and L2 question formation. Applied Linguistics 12(4):416-432. 